\title{
Novel Structured Materials for Structured Catalytic Reactors
}

\author{
Lioubov Kiwi-Minsker*
}

\begin{abstract}
The use of filamentous catalysts for innovative design of chemical reactors with structured catalytic beds is discussed in detail. The fluid dynamics attained in such reactors avoid transport limitations (mixing or heat- and mass-transfer) and increase reactor performance/safety.
\end{abstract}

Keywords: Fiber catalysts · Membrane reactor $\cdot$ Propane dehydrogenation $\cdot$ Structured reactors

\section{Introduction}

Sustainable development of new chemical processes implies the efficient use of materials and energy, and also the minimized formation of toxic emissions and by-products. Such 'green' chemical processes call for innovative concepts in the field of chemical reaction engineering. Up to now the design of chemical processes consisted of adapting the reaction

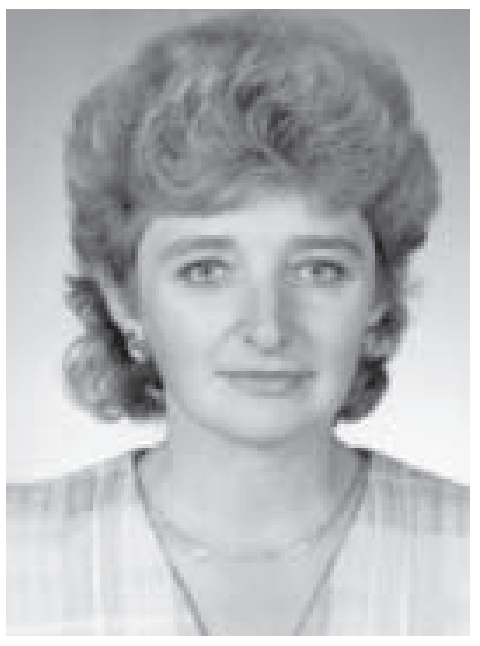

*Correspondence: Dr. L. Kiwi-Minsker Ecole Polytechnique Fédérale de Lausanne Faculté des Sciences de Base

Institut de Sciences des Procédés chimiques et biologiques

CH-1015 Lausanne

Tel.: +41216933182

Fax: +41216933190

E-Mail: lioubov.kiwi-minsker@epfl.ch

http://dcwww.epfl.ch/lgrc/ operating conditions to the equipment available. Commonly catalytic reactors are equipped with randomly packed catalytic beds and have uncontrolled fluid dynamics. This results in stagnation zones and hot-spot formation, broad residence time distribution, low selectivity and finally, low process efficiency. Optimization of these processes is time consuming when modeling reactor performance.

An innovative approach to chemical process development is to design a reactor unit adapted to the chemical reaction. The parameters of the reaction kinetics obtained on the lab scale determine the industrial reactor structure and the geometry of the catalytic bed. In structured catalytic beds the fluid dynamics is imposed on the system, avoiding its modeling and shortening the up-scale procedure. The catalyst properties for the structured reactors should be regulated over multidimensional levels, starting from the nano-designed active surface up to macro-geometry of the catalytic bed.

Monoliths are the most well-known structured catalytic reactors and are widely used in the automobile business although non-transport applications have also been reported [1][2]. Monolithic structures have a high void volume and a large geometric surface area. This results in a low pressure drop during the passage of gases and a large contact area of the catalyst with the reactants. The flow through the honeycomb channels is usually laminar. As the diameters of the channels are in the order of several millimeters, a poor radial mixing and mass transfer limitations from the bulk stream to the catalyst surface takes place. A fur- ther drawback of ceramic monolithic reactors is the non-uniform axial temperature distribution for highly exothermic or endothermic reactions and the susceptibility to mechanical and thermal stress. Therefore, the research and development of novel structured materials for innovative structured reactors is warranted. Herein we report a general approach to the synthesis of structured catalytic materials and their application for the design of reactor units.

Recently we proposed woven fibrous catalysts for the design of structured reactors [3-13]. These catalysts are bidimensional materials, which combine open macro-structures with mechanical elasticity and for this reason are easy to handle. They can be rolled spirally, corrugated and piled up, when filling structured reactors. One supplemental advantage comes from the availability of fibrous supports on the market, since they have a large spectrum of other applications besides their use as catalytic supports. The main materials actually produced on industrial scale are:

i) glass fibers as woven fabrics, gauzes, single threads,

ii) fibrous active carbon fabricated in the form of woven fabrics and

iii) metallic filamentous materials available as woven or knitted gauzes, thin wires and pressed fiber filters.

These materials can be loaded with the catalytically active phase in the form of thin layers or clusters via complex chemistry. We describe below the general approach of the synthesis and optimization of structured catalysts, which addresses three main points: 
- Synthesis. How can the surface of the support be activated in view of its interaction with the metal precursor (e.g. an organometallic complex)? Which metal precursors are the most adequate reagents for the reaction with the active surface species?

- Structure. What are the most suitable methods to characterize the catalyst surface? Can the systematic variation of surface-active species predictably affect the catalyst morphology?

- Catalytic function. How does the surface morphology affect the properties of the ensemble comprising the structured catalyst?

\section{Synthesis of Structured Catalysts}

During the preparation of structured catalyst the sequence followed is 1) surface activation and/or development of high specific surface area (SSA), 2) the deposition of active phase precursor (usually a metal complex), and 3) catalyst activation.

\subsection{Preparation of the High SSA Catalytic Supports and Surface Activation}

As mentioned above, the precursors of structured supports are fibrous commercial materials, like metal fiber filters or gauzes, fiber active carbon (ACF) and glass fibers (GF) in the form of woven fabrics. These materials, with exception of ACF, have a relatively low SSA, which corresponds to the geometrical surface of the fibers. The surface is about $0.1-2 \mathrm{~m}^{2} \mathrm{~g}^{-1}$ depending on the diameter of individual fiber $(2-100 \mu)$. The metallic and glass fiber supports are treated with the aim of increasing their SSA. The treatment of ACF is mostly directed to modulate the surface acidity and functionality. The general scheme of the surface development/activation is presented in Fig. 1. It is seen that metal wires with high SSA were obtained [12] by Me/Al alloy formation on the wire outer surface. After leaching out the $\mathrm{Al}$ component, a thin porous layer was obtained on the metal surface. The morphology of this layer is similar to that found in Raney metals. Oxidation of this layer resulted in a strongly attached porous metal oxide. Formation of this porous outer layer significantly increased the SSA of the grids by up to $20 \mathrm{~m}^{2} \mathrm{~g}^{-1}$. As an example, the Niwire support, consisting of a metallic $\mathrm{Ni}$ core with an oxide $(\mathrm{NiO})$ outer layer is shown in Fig. 2.

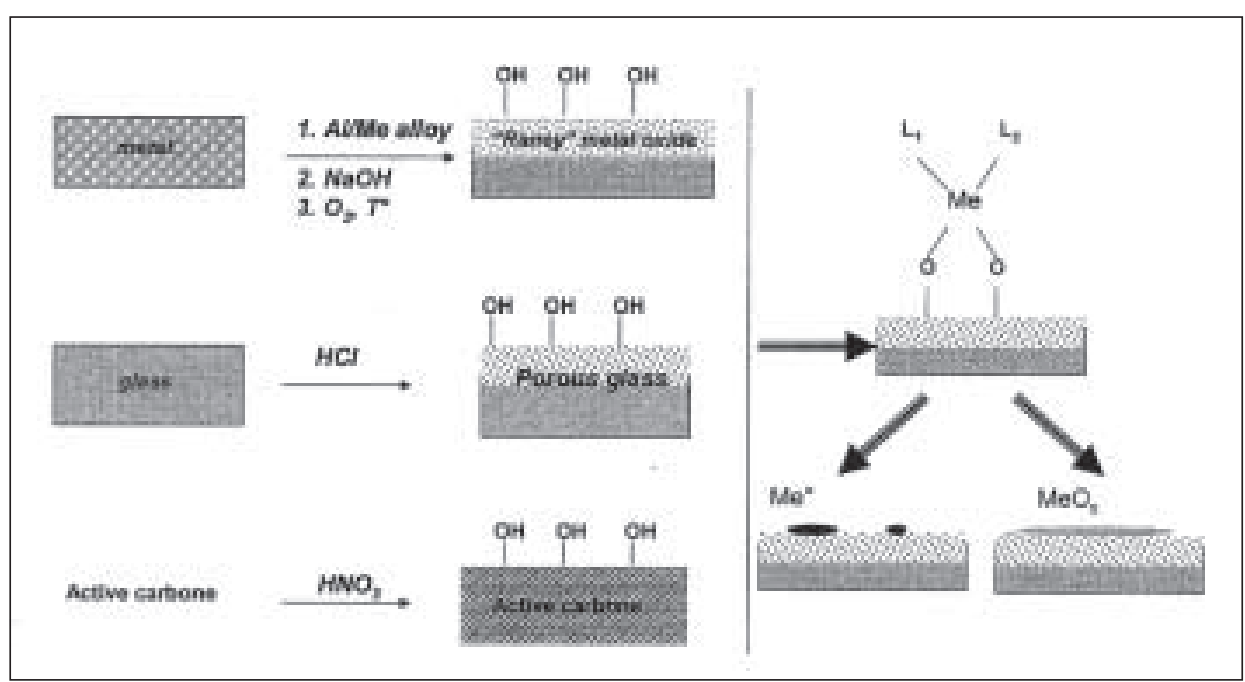

Fig. 1. The general scheme for surface development, activation and the deposition of active phase.

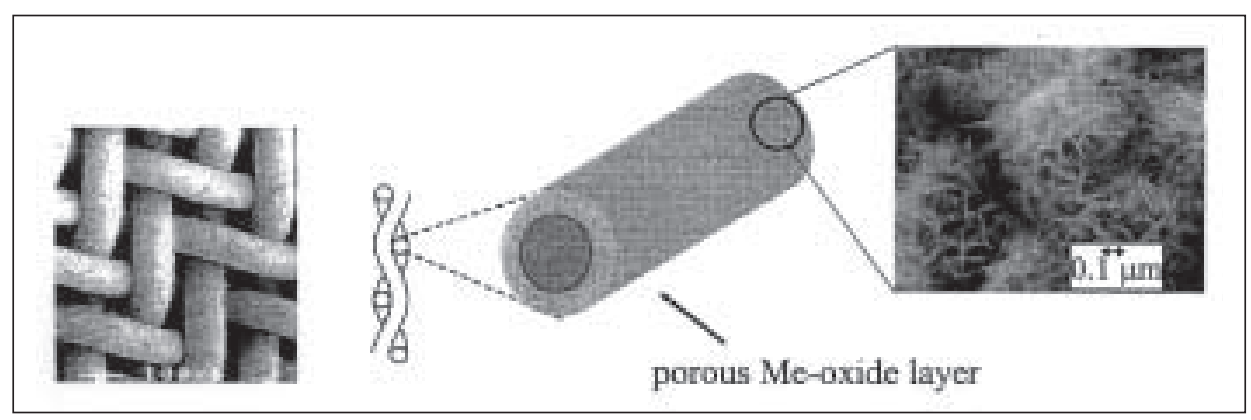

Fig. 2. SEM image of Ni-wire grids and of the surface porous oxide

The development of high SSA woven glass fiber was performed [4][6] by leaching out the non-silica components of commercial fabrics in acidic solutions (see Fig. 1). This treatment created the meso-porosity and varied the SSA from 5 up to $275 \mathrm{~m}^{2} \mathrm{~g}^{-1}$, depending on the temperature and contact time with $\mathrm{HCl}$ solution. The surface of porous glass fibers in some cases was modified by titania, zirconia and alumina to increase thermoand mechanical stability and modulate their surface reactivity. The modification was made by impregnation of the porous glass fibers with aqueous solution of the appropriate salts and consequent calcination on air.

The commercial woven fabrics of ACF have high SSA of $\sim 1000 \mathrm{~m}^{2} \mathrm{~g}^{-1}$ with developed surface micro-porosity. The surface functionality of active carbons is known to be regulated by different pretreatments, e.g. boiling in aqueous $\mathrm{HNO}_{3}$ solution creates oxygen-containing groups and increases surface acidity. In order to obtain ACF supports with moderate acid- ity, the deposition of $\mathrm{FeO}_{\mathrm{x}}$ in the form of small clusters was performed via deposition-precipitation by urea.

\subsection{Deposition of Active Phase}

The activity of supported metals depends on the particle size and the particle interaction with the support. Metal particles of nanometer size (nanoparticles or clusters) have unique properties that bridge those of single molecules and the bulk materials. Due to the high surfaceto-volume ratio and coexistence of different surface planes, these particles have a high free energy resulting in increased chemical reactivity/enhanced selectivity during heterogeneous catalytic reactions. A high dispersion of the metal on the support and a strong resistance of metal nanoparticles to sintering are two goals in the preparation of supported metal catalysts. Depending on the nature and acid/base properties of the support, a suitable Me-complex as a precursor of metal (or $\mathrm{MeO}_{\mathrm{x}}$ ) nanoparticles is used. The Mecomplex is anchored to the supports via 
interaction with surface OH-groups. Precursor deposition is performed from aqueous solution (ion-exchange) or from gas-phase (grafting). For example, on basic supports (alumina, magnesia) the deposition is performed from solutions of noble metals in anionic form $\left(\mathrm{PtCl}_{6}{ }^{2-}\right.$, $\mathrm{AuCl}_{4}{ }^{-}$), while on acidic ones (silica, active carbon) the cations are used (e.g. $\left[\mathrm{Pd}\left(\mathrm{NH}_{3}\right)_{4}\right]^{2+}$, ethylenediamine complex $\left.\left[\mathrm{Au}(\mathrm{en})_{2}\right]^{3+}\right)$. Thus, the surface $\mathrm{OH}-$ groups can be regarded as 'universal linkers' allowing strong interaction of precursor with the support. The formation of a catalytically active phase is the final step of the preparation and includes catalyst drying, calcination, and reduction of the metallic clusters. As an example, the catalyst consisting of $\mathrm{Pt}^{\circ}$-clusters supported on modified glass fiber fabrics is presented in Fig. 3.

\section{Innovative Structured Catalytic Reactors}

Several types of structured reactors can be proposed based on fibrous materials. They have been tested in the com- bustion of hydrocarbons and VOCs [4][6][12], low-temperature CO oxidation, hydrogen production by catalytic cracking [14], propane dehydrogenation to propene [11], liquid-phase hydrogenation [3][5][15], and catalytic water denitrification [7][9][16].

Herein, we present a novel concept of a structured reactor where a micro-channel catalytic bed is formed by long thin filaments (catalytically active fibers) ${ }^{\circledR}$. The reactor consists of a tube (few millimeters in diameter) filled by catalytic fibers (their diameter may be 3-100 $\mu \mathrm{m}$ ) placed in parallel to the tube walls. The particularity of this reactor is that in a tube of conventional dimensions flow hydrodynamics similar to that of multichannel microreactors is created. Therefore, such reactor units could be readily integrated into available technological lines.

Multi-channel micro-reactors are known to have a laminar flow and a short radial diffusion time due to small channel radius. This leads to a narrow residence time distribution (RTD) resulting in high selectivity when operating these reactors. In fact, the channels for gas-flow between the filaments (see Fig. 4) have an equivalent hydraulic diameter in the range of a few microns, also ensuring a laminar flow and a short radial diffusion time. A narrow RTD can be expected through structured filamentous catalytic beds.

The RTD was measured in a tube packed with the threads of glass fibers and with granules of silica and $\gamma$-alumina of different shape and size. Fig. 5 presents the experimentally obtained RTD for filamentous catalytic bed (curve 1) and for the randomly packed beds (curves 2 and 3). The narrower RTD in structured channels is clearly seen in Fig. 5. Under the same experimental conditions, all randomly packed beds demonstrated a significantly broader RTD compared to the structured bed packed by fibers.

The pressure drop during passage of gas through the tube packed with spheres of 100-160 $\mu \mathrm{m}$ was measured and compared to the pressure drop through the structured fiber packing. The hydraulic diameters of both beds are in the same order of magnitude. For the experimental conditions as indicated in Fig. 5, the pressure drop was found to be five times less in filamentous bed compared to randomly packed one.
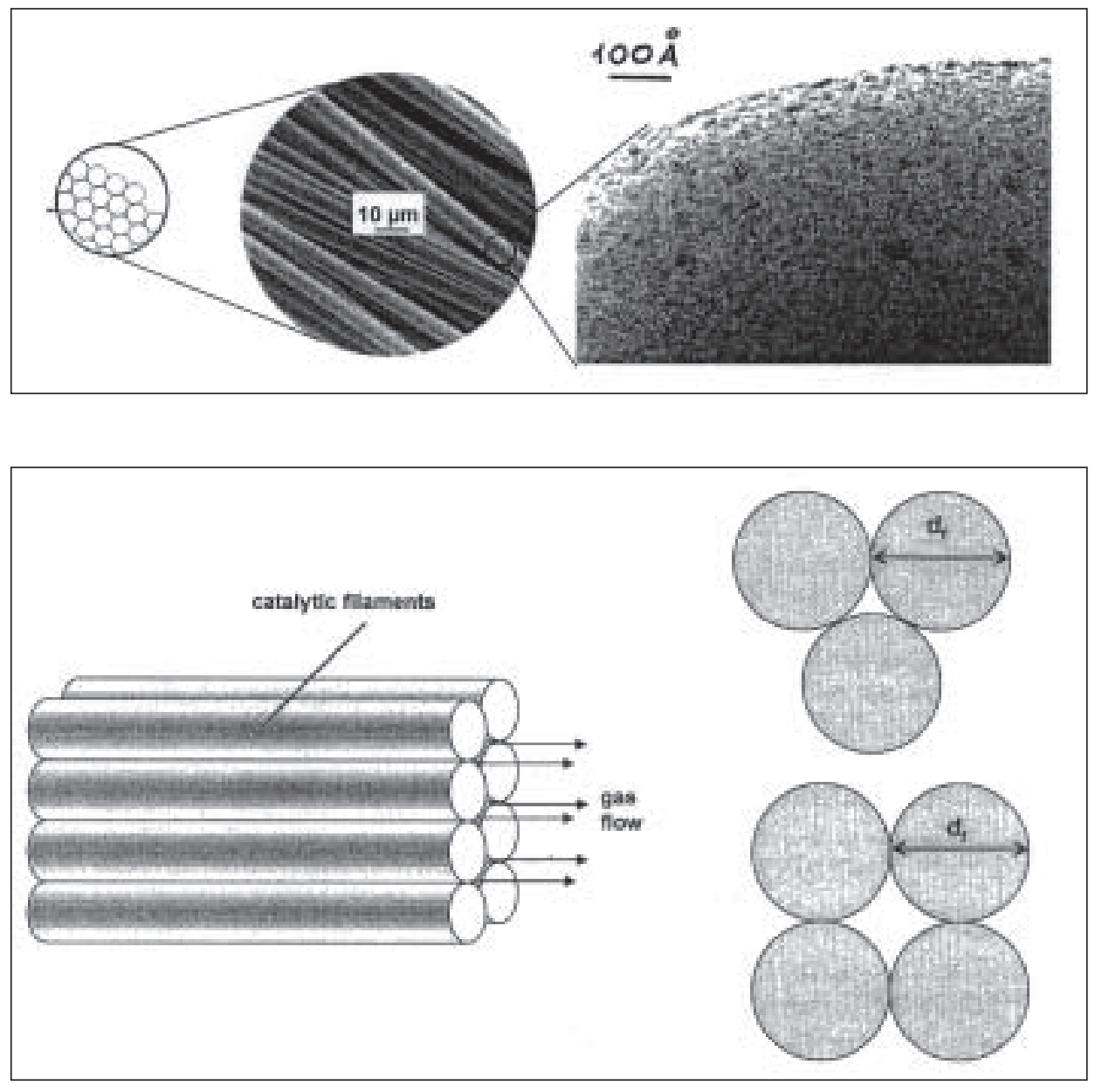

Fig. 3. SEM and TEM images of Pt/glass fibrous catalyst

Fig. 4. Schematic presentation of gas flow between catalytic filaments 


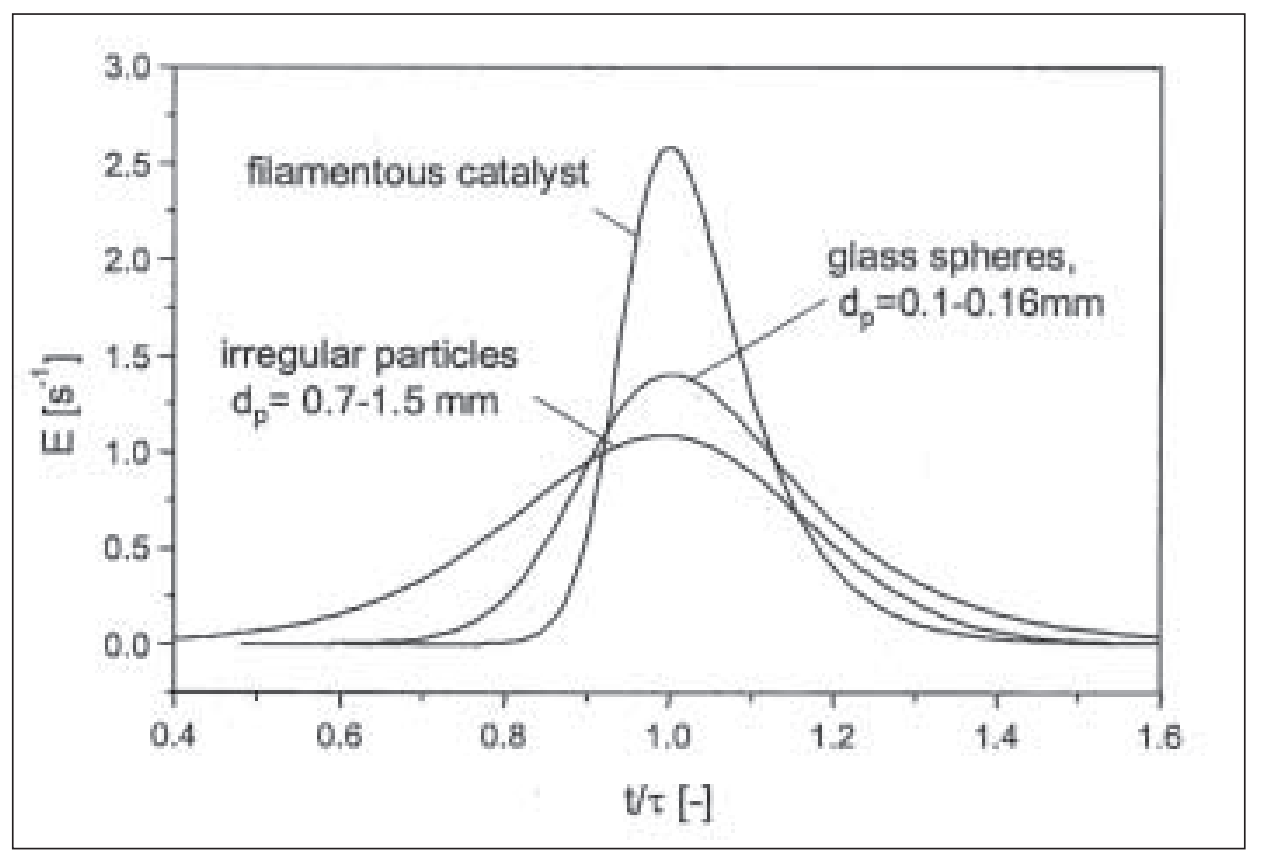

This innovative reactor concept was applied for the non-oxidative dehydrogenation of propane [11]: $\mathrm{C}_{3} \mathrm{H}_{8} \rightarrow \mathrm{C}_{3} \mathrm{H}_{6}+\mathrm{H}_{2}$

This reaction has technological constrains due to the high endothermicity $\left(\Delta_{\mathrm{r}} \mathrm{H}=129 \mathrm{kJmol}^{-1}\right.$ at $823 \mathrm{~K}$ and $\left.0.14 \mathrm{MPa}\right)$ and the unfavourable thermodynamics towards formation of propene (an equilibrium conversion of propane is only $22 \%$ at $823 \mathrm{~K}$ and $0.14 \mathrm{MPa}$ ). Furthermore, at the high temperatures required by the reaction thermodynamics, thermal cracking occurs with coke deposition on the catalytic surface. This deactivates the catalyst and diminishes the selectivity to propene. To regenerate the catalyst, the coke has to be burned off periodically in oxidative atmosphere.

To overcome these constraints a twozone membrane reactor operated periodically is suggested. The reactor design is schematically presented in Fig. 6. The two zones of the tubular reactor with structured fibrous catalytic beds are separated by a $\mathrm{Pd} / \mathrm{Ag}$ membrane permeable to hydrogen. On one side of the membrane (zone I), the dehydrogenation takes place with simultaneous coke formation on the catalyst surface and diffusion of hydrogen to zone II. On the other side of the membrane (zone II), hydrogen is oxidized in an oxygen/nitrogen gas mixture, thus generating heat for the endothermic dehydrogenation in zone I. Moreover, due to the permanent oxidation of hydrogen, a high radial gradient of hydrogen concentration is obtained. This allows an efficient removal of hydrogen from the reaction zone and equilibrium conversion to be exceeded. Simultaneously, with the hydrogen oxidation, the deactivated cata- lyst is regenerated by burning off the coke from the catalyst surface. The feeding of oxygen and propane is periodically switched between the two zones.

A high-surface-area catalyst was prepared from glass fiber threads with the surface modified by alumina and $\mathrm{Pt} / \mathrm{Sn}$ as placed into both reactor zones I and II forming micro-channel structured catalytic beds. The propane conversion and selectivity to propene as a function of time-on-stream are presented in Fig. 7.

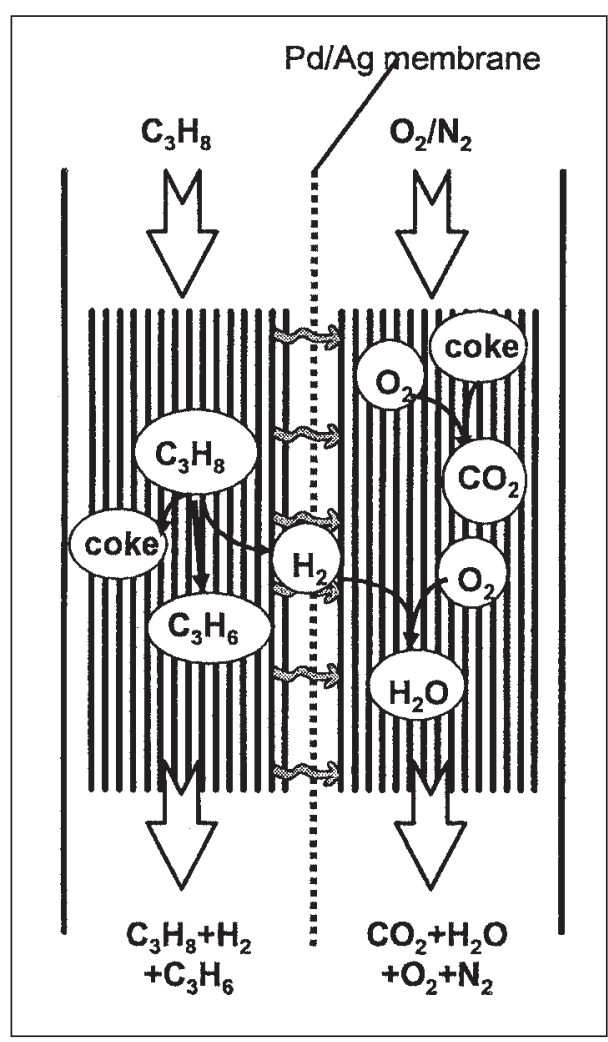
an active component. This catalyst was
Fig. 5. RTD for the structured fiber packing in comparison with the randomly packed catalytic bed
Fig. 6. Scheme of the two-zone micro-channel structured membrane reactor used for propane dehydrogenation 


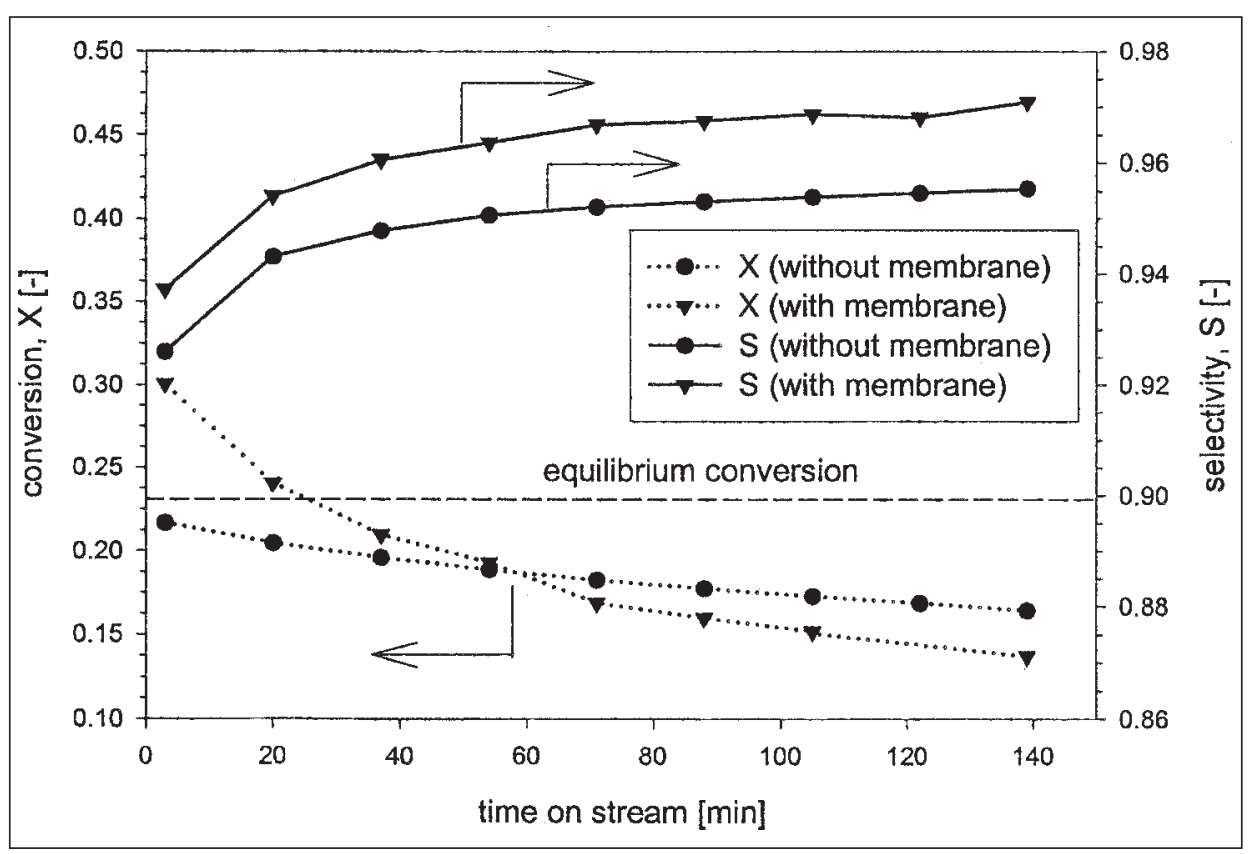

At residence time $19 \mathrm{~s}$, the initial conversion in the membrane reactor reached $30 \%$, exceeding the equilibrium conversion of $22 \%$. Propene selectivity was also enhanced in the membrane reactor: the observed amount of by-products was $50 \%$ and the propene selectivity reached $97 \%$. This effect was explained by the lower concentration of hydrogen in the gas phase, suppressing hydroisomerization and hydrogenolysis reactions.

\section{Conclusions}

Chemical reactors with structured catalytic beds present an innovative approach in chemical reaction engineering, since the fluid dynamics can be imposed on the system, avoiding transport limitations (mixing or heat- and masstransfer).This avoids hot-spot formation, run-away problems and increases the reactor efficiency. Commercial fibrous materials, like metal fiber filters or gauzes, fiber active carbon (ACF) and glass fibers (GF) in the form of woven fabrics are shown to be suitable supports for designing of structured catalyst. Development of high specific surface area and formation of species containing OH-groups activate the surface to retain strongly anchored catalytically active particles.

The use of filamentous materials for structured catalytic beds brings supplemental options in the design of reactors, since it allows hydrodynamics similar to the flow characteristics in micro-channel reactors within units of standard dimen- sions. The benefits of this novel approach were shown by the increased efficiency of propene formation from propane in a membrane structured reactor.

\section{Acknowledgment}

The continuous financial support from the Swiss National Science foundation is gratefully acknowledged. We thank also the CTI commission for supporting this work in the frame of the TOPNANO 21 program.

Received: February 19, 2002

[1] A. Cybulski, J.A. Moulijn, Catalysis Reviews-Science and Engineering 1994, 36, 179.

[2] T. Vergunst, M.J.G. Linders, F. Kapteijn, J. Moulijn, Catalysis Reviews-Science and Engineering 2001, 43, 291.

[3] L. Kiwi-Minsker, I. Yuranov, V. Höller, A. Renken, Chem. Eng. Sci. 1999, 54, 4785.

[4] L. Kiwi-Minsker, I. Yuranov, B. Siebenhaar, A. Renken, Catalysis Today 1999, $54,39$.

[5] V. Höller, D. Wegricht, I. Yuranov, L. Kiwi-Minsker, A. Renken, Chem. Eng. Technol. 2000, 23, 251.

[6] L. Kiwi-Minsker, I. Yuranov, E. Slavinskaia, V. Zaikovskii, A. Renken, Catalysis Today 2000, 59, 61.

[7] V. Höller, I. Yuranov, L. Kiwi-Minsker, A. Renken, Catalysis Today 2001, 69, 175.

[8] V. Höller, K. Radevik, L. Kiwi-Minsker, A. Renken, Ind. \& Eng. Chem. Res. 2001, 40, 1575.

[9] V. Höller, K. Radevik, I. Yuranov, L. Kiwi-Minsker, A. Renken, Applied Catalysis B: Environmental 2001, 32, 143.

[10] B. Louis, C. Tezel, L. Kiwi-Minsker, A. Renken, Catalysis Today 2001, 69, 365.
Fig. 7. Propane conversion and selectivity towards propene in microstructured reactors with and without membrane $(\mathrm{T}=823 \mathrm{~K}, \mathrm{P}=0.14 \mathrm{MPa}$, GHSV $=189 \mathrm{~h}^{-1}, \tau=19 \mathrm{~s}$ )
[11] O. Wolfrath, L. Kiwi-Minsker, A. Renken, Ind. \& Eng. Chem. Res. 2001, 40, 5234.

[12] I. Youranov, N. Dunand, L. Kiwi-Minsker, A. Renken, Appl. Catal. B: Environmental 2002, 36, 183.

[13] E. Joannet, C. Horny, L. Kiwi-Minsker, A. Renken, Chem. Eng. Sci. 2002, in press.

[14] B. Monnerat, L. Kiwi-Minsker, A. Renken, Chem. Eng. Sci. 2001, 56, 633.

[15] V. Höller, D. Wegricht, L. Kiwi-Minsker, A. Renken, Catalysis Today 2000, 60, 51.

[16] Y. Matatov-Meytal, V. Barelko, I. Yuranov, L. Kiwi-Minsker, A. Renken, M. Sheintuch, Appl. Catal. B: Environmental 2001, 31, 233 